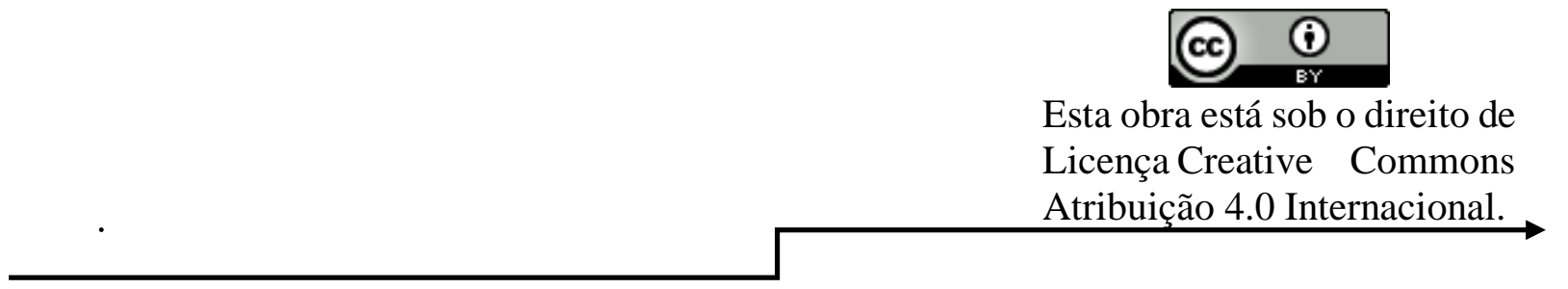

\title{
PAPO DE QUINTA - EDIÇÃO EXPERIMENTAL: Atividades experimentais de baixo custo realizadas pelos estudantes do ensino médio refletindo o processo de ensino aprendizagem em Física durante as aulas remotas da pandemia do sars-cov2 através da plataforma do google meet
}

Genivaldo Ferreira da Silva

Pedro Juvêncio de Souza Júnior ${ }^{2}$

\section{RESUMO}

A pandemia do Sars-Cov2 impôs uma nova realidade para todos. Para os profissionais da educação não foi diferente e passaram a ter suas atividades curriculares realizadas remotamente. Tudo isso para evitar o contágio do novo coronavírus e manter o distanciamento social. Devido a este fato buscamos estratégias para a manutenção das aulas e consequentemente o contato com os estudantes, visto que as atividades educacionais também passaram por adaptações para serem realizadas, nisso, propomos aos estudantes aulas experimentais com matérias de baixo custo com materiais encontrado em suas residências e pudessem desenvolver suas experiencias para a área de ciências da natureza. Este trabalho foi desenvolvido com os estudantes do Centro Estadual de Educação profissional e Marcelo Dêda Chagas localizada no interior do estado de Sergipe e vimos através deste compartilhar nossa experiencia exitosa com as experimentações caseiras que nos proporcionou uma dinâmica prazerosa frente as aulas remotas da disciplina de Física nesses tempos de pandemia do Sars-Cov2 e reforçando o distanciamento social. Assim, neste artigo propomos a síntese da desenvoltura dos estudantes nas experimentações confirmando a participação de cada um deles reforçando a atuação dos estudantes enfatizando o protagonismo dos estudantes e os benefícios para o seu aprendizado. Concluímos, pois, que o interesse dos estudantes frente à novas formas de aprendizagem através do google meet colabora para o processo de ensino aprendizagem, sabemos que não é $100 \%$ eficiente, mas são inteiramente significativas e que colaboram para o seu aprendizado em tempos de distanciamento social em que vídeos e mensagens virtuais passaram a ser os materiais didáticos dos estudantes e as ferramemtas de trabalho de professores.

Palavras-chave: Ensino Remoto. Física. Pandemia. Experimentos.

\footnotetext{
${ }^{1}$ geni.herreira@gmail.com

2 pedro.juvencio@ifal.edu.br
} 


\section{INTRODUÇÃO}

De uma hora para a outra, a pandemia do Sars-coV2 impôs uma nova realidade para milhares de professores e alunos em todo país. E de repente vimos o giz e a lousa serem substituídos por plataformas on-line. Vídeos e mensagens virtuais - passaram a ser os materiais didáticos dos estudantes e as ferramemtas de trabalho de milhares professores, procedendo a garantia do isolamento social e a tentativa de evitar a proliferação da covid-19.

Assim, o distanciamento social causado pela pandemia do Sars-coV2 tem dificultado e modificado a rotina de todos os cidadãos e de todos os profissionais que passaram a dedicar sua rotina de trabalho em casa para se adaptar a essa nova realidade. Vimos que tanto para os professores quanto para os estudantes não foi diferente, pois o ensino remoto caiu como uma "bomba" para todos que se negavam a utilizar as tecnologias como forma de aliar a processo de ensino aprendizagem. Visto que com a disseminação da pandemia "todos" os estudantes e os professores tiveram que associar e adaptar a sua realidade ao ensino remoro trazendo à tona as grandes discrepâncias que a educação apresentava.

\footnotetext{
${ }^{1}$ Modalidade de ensino que une o ensino tradicional presencial, em que o processo ocorre em sala de aula,
}

Como a pandemia só veio acelerar o Blended Learning ${ }^{1}$ no ensino médio inserindo o uso das tecnologias de informação e comunicação no processo de ensino aprendizagem dos jovens no seu cotidiano, coube aos professores novos alinhamentos como o uso de novas plataformas que agregam diversas ferramentas que possibilitem o aprendizado dos estudantes. As aulas virtuais se tornaram a melhor forma de substituir o convívio da sala de aula, trazendo a compreensão mesmo que tardia em alguns setores que elas seriam suficientes para que o ano letivo de 2020 não passasse em branco e isso proporcionou a participação dos pais e "valorização"2 dos professores. É o que aponta um estudo realizado pela fundação Lemann sobre uma pesquisa realizada pelo DATA FOLHA (2020) que de acordo com o estudo 'Educação não presencial na perspectiva dos estudantes e suas famílias' apontou que $51 \%$ dos responsáveis consideram que estão participando mais da educação dos estudantes, no período da pandemia. Este índice sobe para 58\% na região Sul e 57\% no Centro-Oeste. Também aumenta para $58 \%$ entre os responsáveis com maior escolaridade, contra $47 \%$ entre os que têm nível fundamental. E $72 \%$ concordam com

e o on-line, que utiliza as tecnologias digitais para promover o ensino.

${ }^{2}$ Tornando-os bem visto 
a afirmação de que estão com mais responsabilidade pela educação dos estudantes durante a pandemia, do que antes dela. O levantamento aponta que $71 \%$ dos responsáveis pelos estudantes estão valorizando mais o trabalho desenvolvido pelos professores e $94 \%$ consideram muito importante que os docentes estejam disponíveis para correção de atividades e esclarecimento de dúvidas durante às aulas não presenciais. Outro efeito importante da pandemia para a educação é que a maioria (64\%) também considera que às aulas não presenciais foram eficientes no aprendizado aos estudantes, enquanto $36 \%$ afirmam que não foram eficientes. Os resultados também revelaram dados sobre o acesso aos conteúdos. Em setembro, 92\% de estudantes brasileiros receberam atividades para fazer em casa, contra $74 \%$ em maio. O aumento ocorreu em toda as regiões do país, sendo o Norte (84\%) a com menor índice de acesso.

Assim as novas formas de ver o processo de ensino-aprendizagem surgiram e os estados e municípios brasileiros chegaram a concluir que a modalidade remota nesses tempos seriam o "suficiente", visto que muitos estudantes não tiveram acesso pelas condições financeiras ou outros fatores que colaboraram para tal. A reinvenção por parte dos professores em suas áreas foi necessária, e a das Ciências da Natureza e suas Tecnologias enquadras pela $\mathrm{BNCC}^{3}$ não foi diferente.

Tendo em vista o que trata a Constituição Federal de 1988, em seu art. 205, no qual dispõe ser direito de todos e dever do Estado e da família, sendo promovida e incentivada com a colaboração da sociedade. Nesse sentido, considerando um cenário de suspensão das atividades presenciais, o Conselho Nacional de Educação, instruiu os sistemas e às redes de ensino, de todos os níveis, etapas e modalidades, sobre a necessidade de novas formas de atividades escolares e acadêmicas por conta de ações preventivas à propagação da COVID-19, ou seja, para a utilização das plataformas de ensino de conteúdos e recursos virtuais.

Segundo COSTA (2020) é marcante que não se pode estabelecer qualquer estratégia sem a escuta e a participação dos professores, das famílias e toda a comunidade escolar, assim como a proposição de políticas não podem ser reduzidas a meras atividades curriculares mediadas pela tecnologia. Nestes termos, a deferência aos princípios que orientam o uso da educação a distância e o uso de quaisquer dispositivos de ensino remoto implica, entre outros, no planejamento e 
gestão compartilhada, domínio e autonomia dos sujeitos para o acesso aos recursos disponíveis, e de igual maneira o acompanhamento e avaliação, ademais, a pesquisa e extensão, inovação e orientação de estudantes a distância, com o uso e o acesso às tecnologias de comunicação e informação, carecem de mais análises a serem realizadas, seja sobre o investimento necessário para dar suporte aos professores, seja sobre a realidade dos estudantes que precisam de acesso.

A partir das novas adaptações realizadas pelos estados e pelas instituições educacionais vimos a necessidade de colocar em prática nos estudos da disciplina

\section{REFERENCIAL TEÓRICO}

É comum observar que em algumas escolas de ensino médio não se tenha laboratório de ciências e em outras possuam e os materiais estejam sucateados, todavia não realizam atividades experimentais e isso já acontece costumeiramente, sendo que a maioria dos professores não são ou não estão preparados para esse tipo de ação que deveria ser oferecida aos estudantes.

Assim, de acordo com as colocações de Rodrigues (2018) apud Araújo; Abib, (2003, p. 176). Estes apontam que quando se pode medir e analisar informações obtidas fisicamente a partir de observações reais com a finalidade de alcançar um resultado aplicável ao mundo, o de Física nas 3 séries $\left(1^{\mathrm{a}}, 2^{\mathrm{a}}\right.$ e $\left.3^{\mathrm{a}}\right)$ do ensino médio de uma escola técnica de Sergipe o uso do projeto experimentação virtual para realização de atividade não presencial nesses tempos de pandemia.

O projeto virtual surgiu como forma de dinamizar e integrar os estudantes durante o distanciamento social, de forma que tivessem acesso a experimentação sendo estes de forma simples e acessível, tentando abranger os conhecimentos adquiridos de forma lúdica.

Assim, pudessem realizar atividades experimentais durante esse período tornando as aulas remotas mais dinâmicas e atraentes.

entendimento do fenômeno físico envolvido fica amplamente mais claro. Desse modo, é de se concordar que "o uso de atividades experimentais como estratégia de ensino de Física tem sido apontado por professores e alunos como uma das maneiras mais produtivas de minimizar as dificuldades de aprender e ensinar Física”.

De fato, pois é através de experimentos e experimentações que os estudantes podem chegar a sua totalidade a respeito do conteúdo estudados. Visto que eles podem até associar a sua realidade trazendo à tona realidades nunca imaginadas ou vividas pelos estudantes. E ainda, mesmo que seja da forma mais simples possível utilizando materiais simples e de fácil acesso, tornando-os assim 
protagonistas de seu próprio conhecimento enfrentando todas as dificuldades propicias da disciplina e do próprio ensino enraizado no tradicionalismo. Como menciona Medeiros et al (2018) apud Zambom (2008) afirma que uma das formas de enfrentar tais dificuldades e deficiências consiste em organizar um ensino que seja baseado em recursos e materiais didáticos diversos.

Ainda que, menos não possuindo aparatos para realização de experimentos, visto que este são muito caro e os estudantes não tem recursos financeiros que arquem com tais atividades e é exatamente defende Medeiros et al (2018) apud Ramos (1990), alguns materiais caros podem trazer um desconforto ao serem manipulados por alunos inexperientes e podem não trazer um contato real entre o aluno e o conhecimento explícito. E isso é o que os professores de física pretendem e que os alunos possam demostrar com os simples materiais que possam usar.

\section{As aulas remotas de física na pandemia do sars-cov2 e o uso da experimentação com materiais simples como estratégia metodológica}

Não comum no novo meio educacional o uso de link do google meet, salas virtuais, smartfones, Notebooks e grupos de Whatsapp se tornaram as ferramentas necessárias virtuais para a aprendizagem, não só dos estudantes, mas também dos professores que buscaram se adaptar a essas novas ferramentas junto com os estudantes, mesmo pegas de surpresa.

Nesse sentido, escolas públicas receberam poucas orientações na adaptação do ensino presencial ao ensino remoto. É preciso reconhecer que não só o acesso precisa ser foco dos governos, mas também o formato do aprendizado oferecido aos alunos e que estes percebam sua função. Não se trata apenas de gravar vídeos ou criar apresentações, mas moldar todo o conteúdo para diferentes mídias afim de buscar o conhecimento através das ferramentas acessíveis.

Como atividades alinhadas à Base Nacional Comum Curricular (BNCC), os recursos digitais adaptativos e gameficados nos formatos de quizzes e games que dialogam com o aluno do Século XXI através de elementos visuais e sonoros promovem a compreensão de conceitos matemáticos abstratos em um ambiente engajador, lúdico e multissensorial fazendo-o interagir com as diversas áreas do conhecimento. Essas formas digitais são elementos que as várias áreas incrementaram e as ciências da natureza também incorporou esses recursos somado as atividades de experimentação com materiais simples que veio colaborar com a necessidade de inovar na realidade que nos convinha.

Como diz Lagarto et al (2020) "O ensino online de emergência caracteriza-se 
por uma separação física entre o aluno e professor, separação essa que não foi planejada e que resulta de uma situação de emergência. A tendência, nestes casos, é de transportar para a distância os conteúdos e o formato das aulas presenciais, e manter os alunos num regime de aulas síncronas e de acordo com os horários estabelecidos para as aulas presenciais". E que tem se tornado um desafio, mais um que os professores

\section{METODOLOGIA}

Quanto à abordagem, a metodologia utilizada foi de natureza qualitativa sistemática, por se mostrar mais adequada para o tipo de situação que nos convinha. Os instrumentos utilizados para coleta de dados foram observação o tipo de experimento realizado de acordo com o ano/série do estudante. As atividades foram desenvolvidas semanalmente para culminância do projeto de forma virtual que ocorreu durante as 4 semanas do mês de janeiro de 2021 sendo que sua utilização surgiu como uma alternativa frente a necessidade de os alunos conhecerem o aspecto experimental exigido pela disciplina de Física. Daí, afim de proporcionar um alivio nas demandas e obter um rendimento mais frente a nossa realidade, é que surgiu a oportunidade de utilizá-lo com os alunos da escola técnica estadual numa cidade do interior do estado de Sergipe fazendo os experimentos com encontram para se adequar a realidade que lhe são impostas muitas vezes dentro do campo educacional. Daí, surge, a reflexão feita por Nogueira (2020) que: Necessidade de distanciamento social na pandemia mostrou importância do acesso à internet e a computadores para escolas, professores e estudantes. Ensino híbrido terá de passar a fazer parte da realidade da educação pública após a quarentena.

materiais de fácil acesso. A recepção foi a mais promissora possível, propiciando o interesse dos estudantes e aqueles mais interessados em aparatos tecnológicos, se engajando muito bem no "novo" frente ao que disciplina poderia oferecer.

Optamos por apresenta-los a "nova" ferramenta e usá-la nos moldes off-line através da gravação de vídeos de pouco mais de 1min:50 segundos devido aos fatores de falta de internet ou outros problemas relacionados a isso, repercutindo melhor nas atividades propostas pelo professor.

\section{A experimentação com materiais simples nas aulas remotas de física realizadas pelos estudantes}

Não diferente no período de distanciamento social de acordo com Cardoso; Takahashi (2011) é de conhecimento corrente que os alunos geralmente possuem dificuldade em aprender física. Esse fato se agrava, 
também, devido a problemas na formação inicial e continuada dos professores e à falta de atividades práticas nessa disciplina, principalmente na educação básica, onde a carência de equipamentos de laboratório didático nas escolas impede a realização de experimentos. De fato, e se agrava mais ainda com a suspensão das aulas presenciais dificultando o acesso dos estudantes.

Para Força (2019) “os trabalhos com atividades experimentais contribuem para que os alunos se tornem ativos no processo de aprendizagem [...] argumenta que o trabalho prático nem sempre necessita incluir atividades que se desenvolvam em banco de laboratório" e ainda completa com que SEED (2008, p.74) considera: “experiências que permite a manipulação de materiais pelos estudantes ou uma demonstração experimental pelo professor, nem sempre precisa estar associada a um aparato sofisticado. Importa à organização, discussão e reflexão sobre todas as etapas da experiência, o que propicia interpretar os fenômenos físicos e trocar informações durante a aula, seja ela na sala ou no laboratório".

Pretendemos discutir aqui neste artigo como estudantes poderiam realizar experimentos se os mesmos estavam em isolamento social devido a pandemia do SARSCOV2? E se as atividades experimentais poderiam aprendizado. Baseado nestas condições é que ressaltamos o que Leiria; Mataruco (2015) salienta: “o uso dessa metodologia porque os alunos, em geral, não gostam da disciplina, mas gostam de realizar experimentos no laboratório. E a motivação é um dos pilares de sustentação da eficiência do processo ensino aprendizagem e as atividades experimentais desempenham essa função muito bem"

Ainda Rodrigues (2009) reforça: “A experimentação atua como mola-mestra no ensino de ciências, servindo para demonstração de fatos e conceitos científicos, bem como para despertar a curiosidade dos alunos e para incentivar novas descobertas".

Assim, a experimentação de baixo custo assume um papel muito promissor
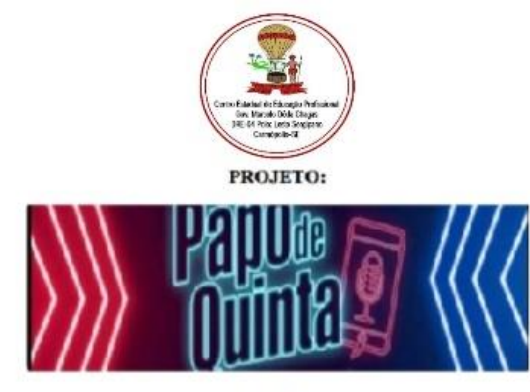
Experimental
nesses casos de pandemia e distanciamento social. Visto que é a única forma que os alunos possuem de mostrar seu interesse pelas ciências naturais e que podem corroborar com o aprendizado dos estudantes realizando a experimentação simples e que possam explorar os diversos conteúdos que a disciplina apresenta. 


\section{PAPO DE QUINTA - EDIÇÃO EXPERIMENTAL: A da plataforma do google meet dando suporte para aprendizagem}

Esta ação educacional foi idealizada a partir do projeto "PAPO DE QUINTA" que buscava integrar alunos e professores convidados para debate de diversos assuntos do meio educacional. Surgindo de forma promissora para os estudantes mostrar seus trabalhos experimentais realizados com materiais caseiros e que pudessem ser analisados e discutido a ciência envolvida nos mesmos.

Buscamos atrelar os aparatos tecnológicos dos estudantes com as novas formas de aprendizagem e propor uma atividade científica experimental a distância que dispusesse seus interesses para com a disciplina de Física. Através de vídeos gravados realizando suas experiencias de forma simples e prática.

De acordo com o que apuramos, a opinião dos estudantes é bem promissora sobre a utilização da experimentação e exibição na categoria remota sendo que estas realizada em suas residências para as aulas virtuais de Física e observamos que os resultados se apresentaram bem proveitosos como podemos observar nas respostas dos alunos das $1^{\circ}, 2^{\circ}$, e $3^{\circ}$ séries dos cursos integrados de uma escola estadual do estado de Sergipe. Vejamos suas opiniões a respeito da atividade:

\begin{tabular}{|c|c|c|}
\hline \begin{tabular}{ll|l}
$17 / 202120: 41: 03$ & $3^{\circ} \mathrm{ST}$ \\
\end{tabular} & muito bom, aprendemos muito com cada experimento. & \\
\hline 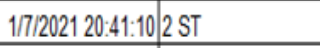 & Achei muito bom as apresentaçôes dos experimentos. & \\
\hline 1/7/2021 20:41:21 2 ano PG & \begin{tabular}{|l|l|} 
Maravilhoso, os experimentos foram incriveis! & \\
\end{tabular} & \\
\hline 1/7/2021 20:41:30 $11^{\circ}$ Mecânica & Gostei da participação de vários alunos e dos experimentos apresentados. & \\
\hline 1/7/2021 20:41:31 $11^{\circ}$ ano | Mecânica & \multirow{2}{*}{\multicolumn{2}{|c|}{$\begin{array}{l}\text { Quase inaplicável, junto ao experimento aprendemos muitooo com os ensimentos do experimento. } \\
\text { MUITOOOO BOMMM os experimentos foi muito bom }\end{array}$}} \\
\hline 1/7/2021 20:41:39 1 1'Mecânica & & \\
\hline \begin{tabular}{|l|l|l|l|l|l|l|l} 
1/72021 20:41:49 & $1^{\circ}$ Química \\
\end{tabular} & Legal, os videos dos experimentos estavam incriveis & \\
\hline \begin{tabular}{l|l|}
$1 / 7 / 202120: 41: 52$ & 2 ano ST \\
\end{tabular} & Ameiiil! Adorei a proposta da aula, super dinâmica e objetiva. & \\
\hline 1/7/2021 20:43:37 $22^{\circ}$ Petróleo e Gás & Foi sensacional.As apresentaç̣̂es foram incriveis e muito bem explicativas. & \\
\hline 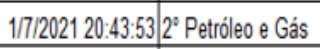 & \multicolumn{2}{|c|}{ Legal, foi interessante ver alguns experimentos e foram todos ótimos, todos os grupos souberam apresentar } \\
\hline 1/7/2021 20:44:10|2-ST & \multicolumn{2}{|c|}{ Fantástico,com tantos experimentos incriveis de cada sala e com uma explicação bem elaborada de cada experimento. } \\
\hline
\end{tabular}

\begin{tabular}{|c|c|}
\hline 1/14/2021 20:47:24 20 Ano Petróleo e Gás & Incrivell Os expreimentos e as apresentaçöes foram super empolgantes e muito curiosas. \\
\hline $1 / 14 / 202120: 47: 27 / 2 P G$ & Incrivell! Experimentos impecáveis, mas não aproveitei muito devido a minha internet \\
\hline 1/14/2021 20:48:02 2ST & Está sendo muito bom desde a volta dos papos de quinta, e com os experimentos ficou mais interessante. \\
\hline 1/14/2021 20:48:392-ST & Maravilhoso, por conter vários experimentos incriveis, além disso,tendo müto conhecimento sobre determinado assunto apresentado. \\
\hline 1/14/2021 21:03:03 1 ano st & Como sempre muito dinâmico \\
\hline
\end{tabular}

As respostas dos estudantes são propicias a realidade que nos convém e mesmo em distanciamento social eles usam as mais diversas facetas para se dar bem durante a realização da atividade explicando seus trabalhos apresentados em tempo real pela plataforma google meet. 
Um dos destaques encontra-se no link <https://youtu.be/vwB7qhPtmrI> tratando sobre a aplicação das leis de Newton.

Os estudantes ainda se colocam sobre o evento como uma boa alternativa de aprendizado e suas interações nas redes sociais demostram suas inquietações na riqueza do projeto que lhes proporcionou aprendizagem. Tudo através da orientação do professor.
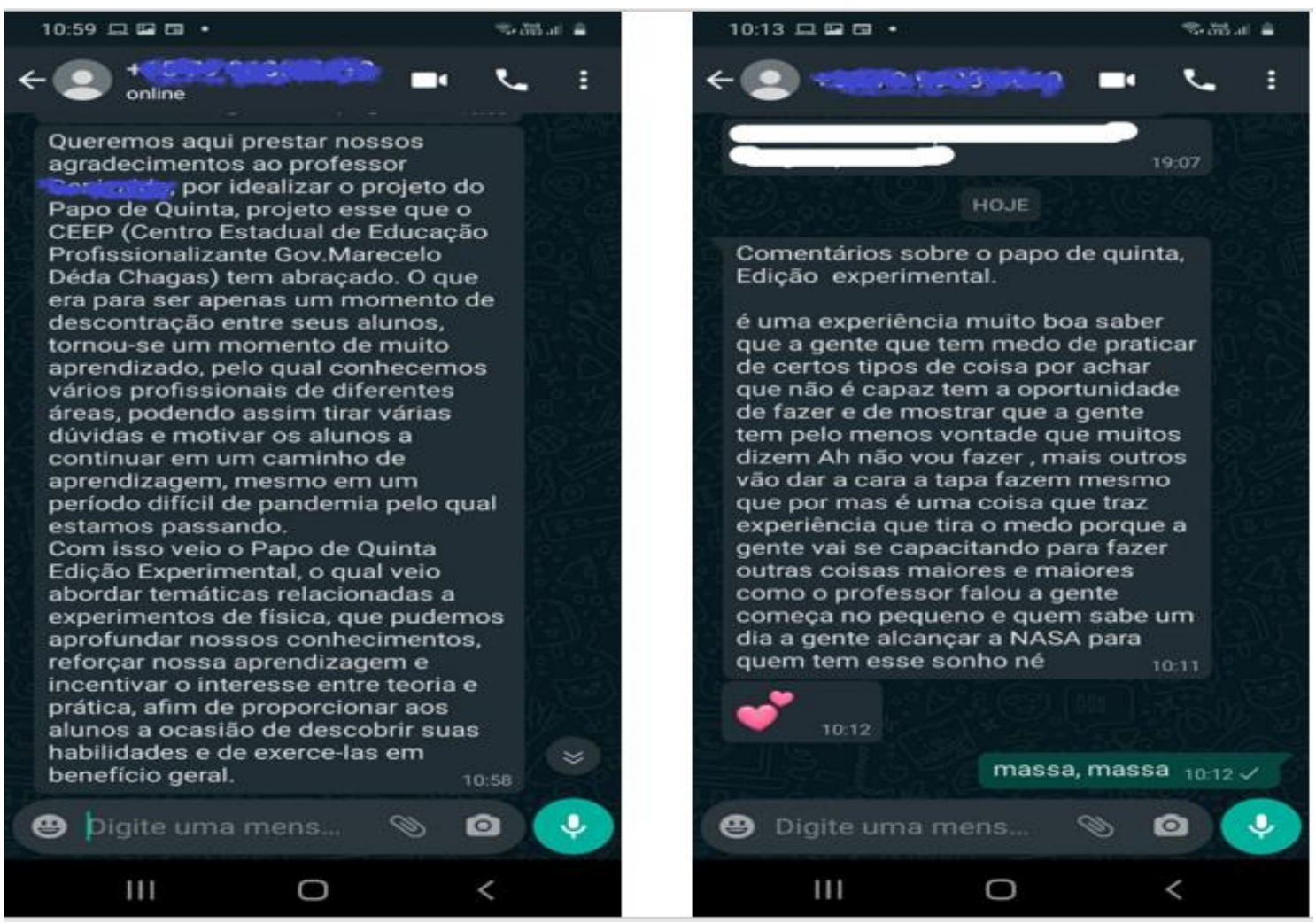

Fonte: Autoria própria.
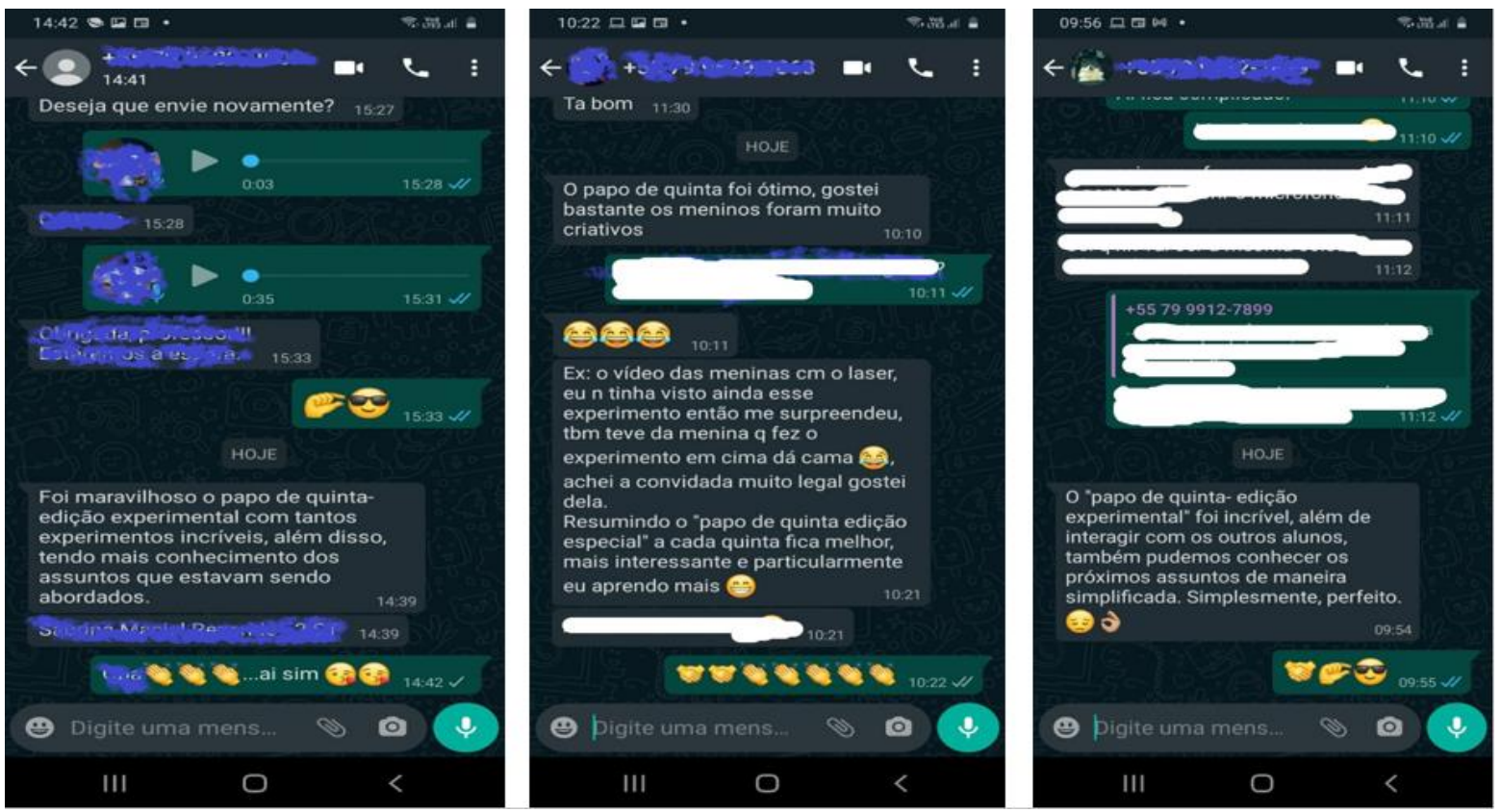

Fonte: Autoria própria. 


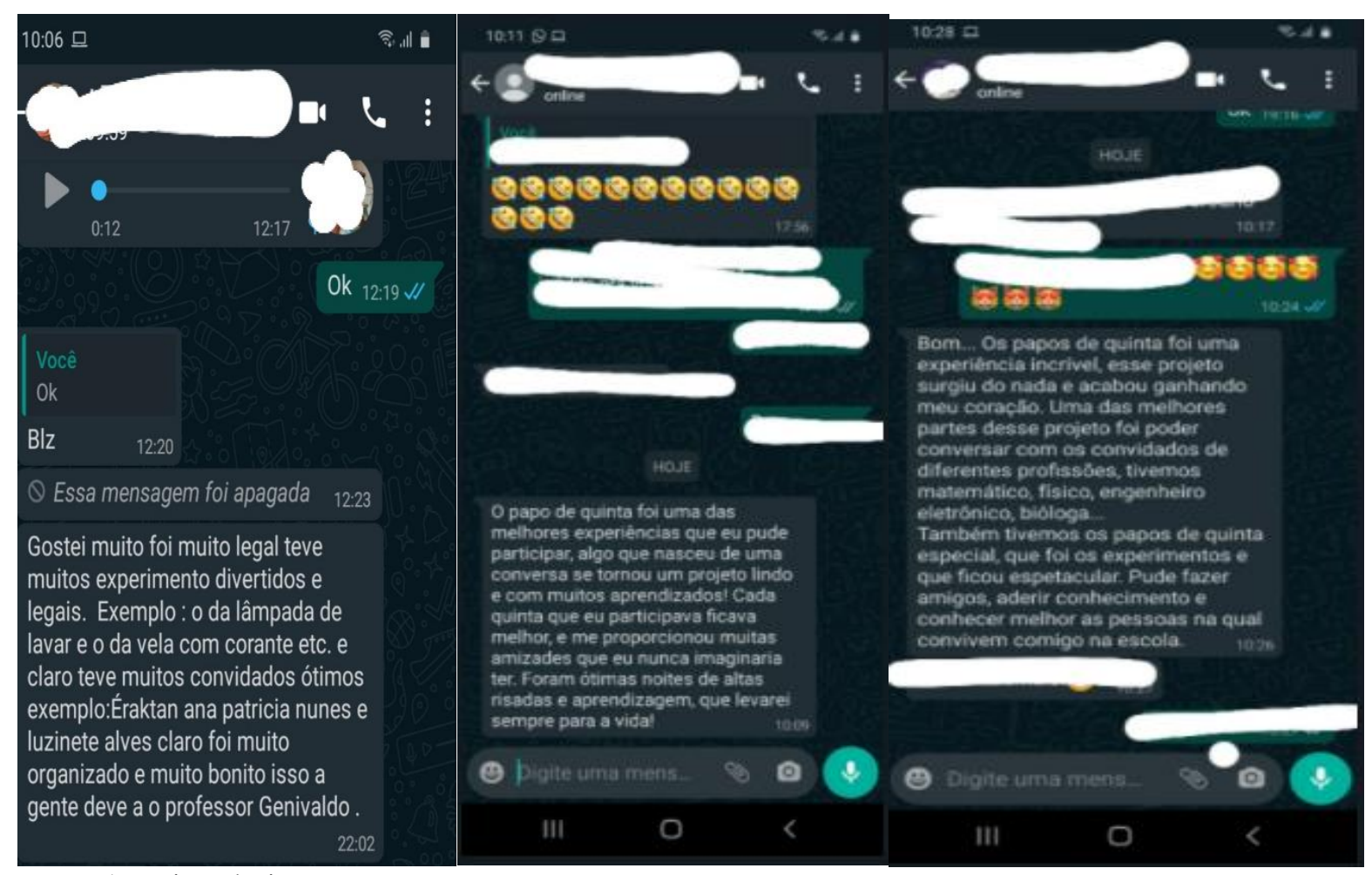

Fonte: Autoria própria.

\section{Experimentações caseiras com materiais simples}
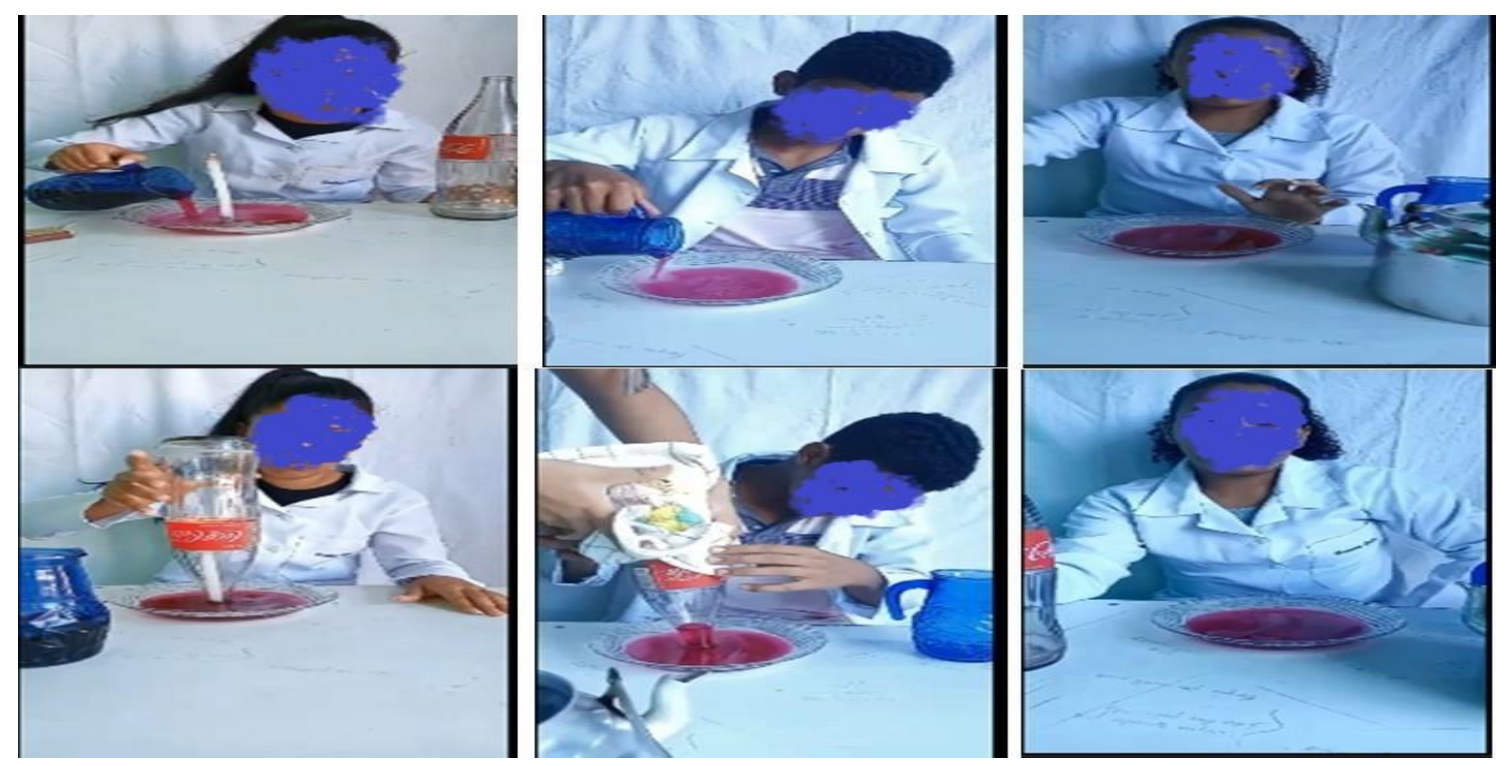

Fonte: Autoria própria.

Experimentos caseiros realizados pelos estudantes da turma $1^{\mathrm{a}}$ série do ensino médio do curso integrado em química, e exibido pela plataforma google meet.

Experimento sobre pressão atmosférica. 

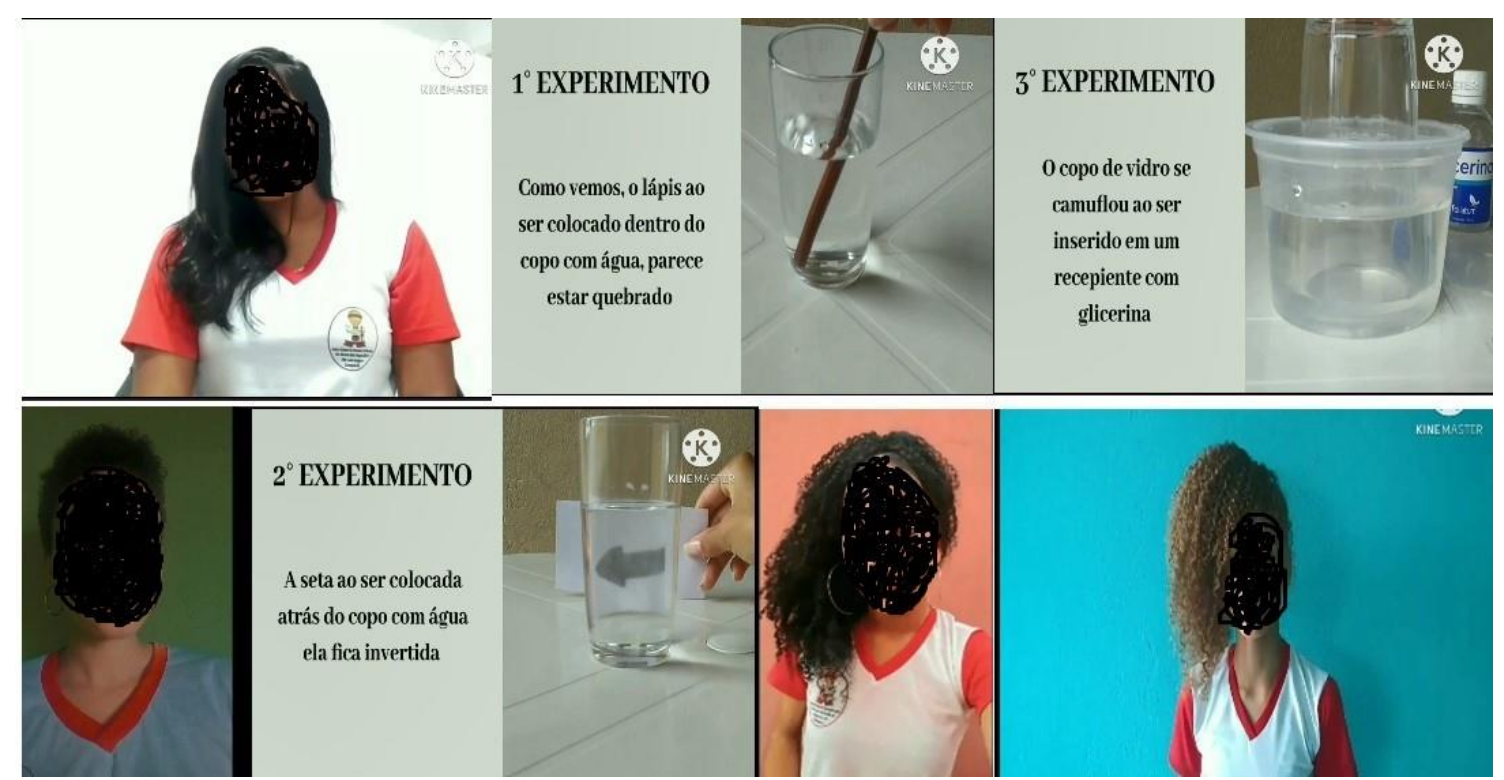

Fonte: Autoria própria.

Experimentos caseiros realizados pelos estudantes da turma $2^{\mathrm{a}}$ série do ensino médio do curso integrado em Segurança do trabalho e exibido pela plataforma google meet. Experimentos sobre refração da luz
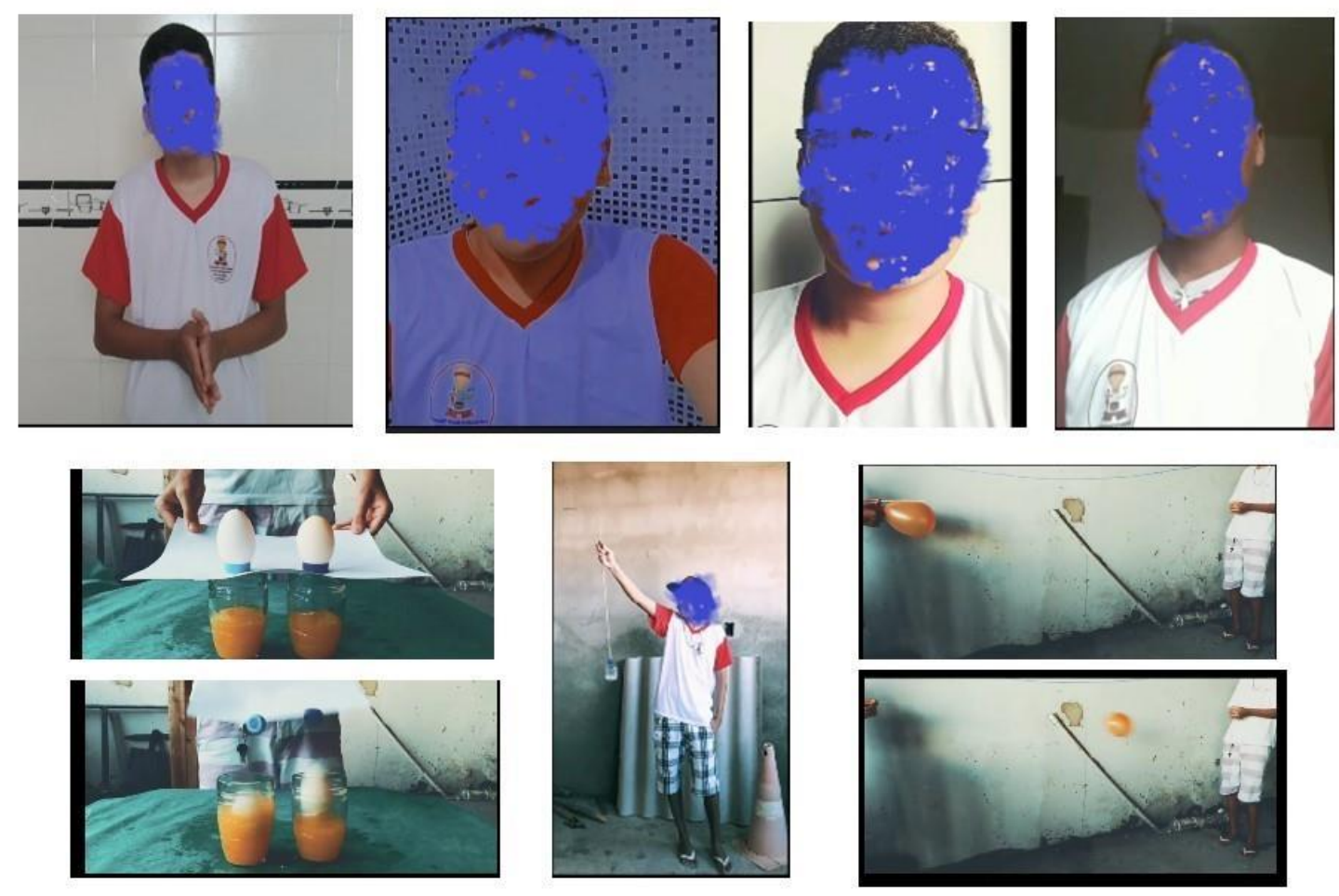

Fonte: Autoria própria.

Experimentos caseiros realizados pelos estudantes da turma $1^{\mathrm{a}}$ série do ensino médio do curso integrado em Mecânica do trabalho e exibido pela plataforma google meet. Experimentos sobre leis de Newton. 


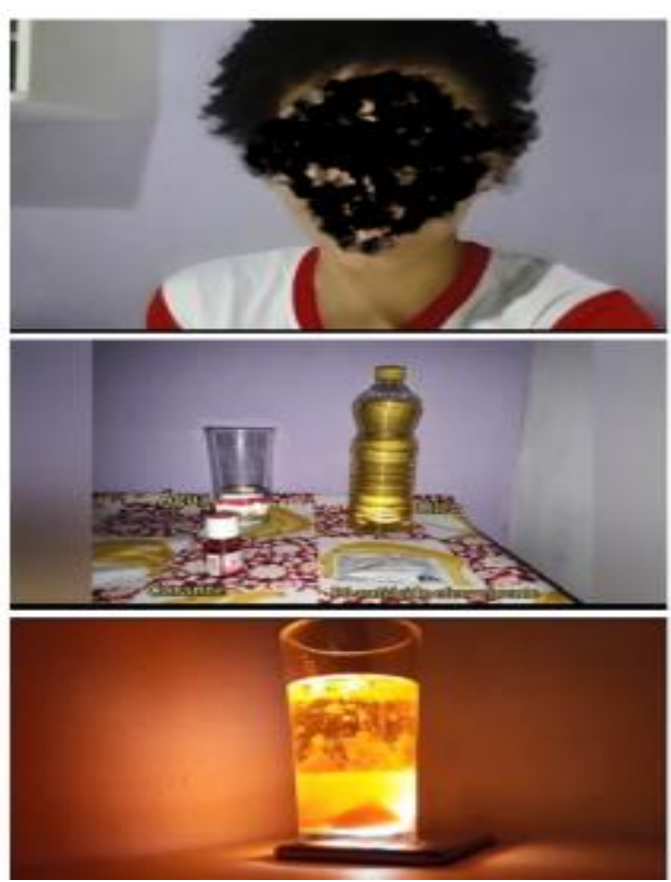

( 1 )

Fonte: Autoria própria.

Experimentos caseiros realizados pelos estudantes da turma $1^{\mathrm{a}}$ série (1) e $2^{\mathrm{a}}$ Série (2) do ensino médio do curso integrado em Química e Segurança do
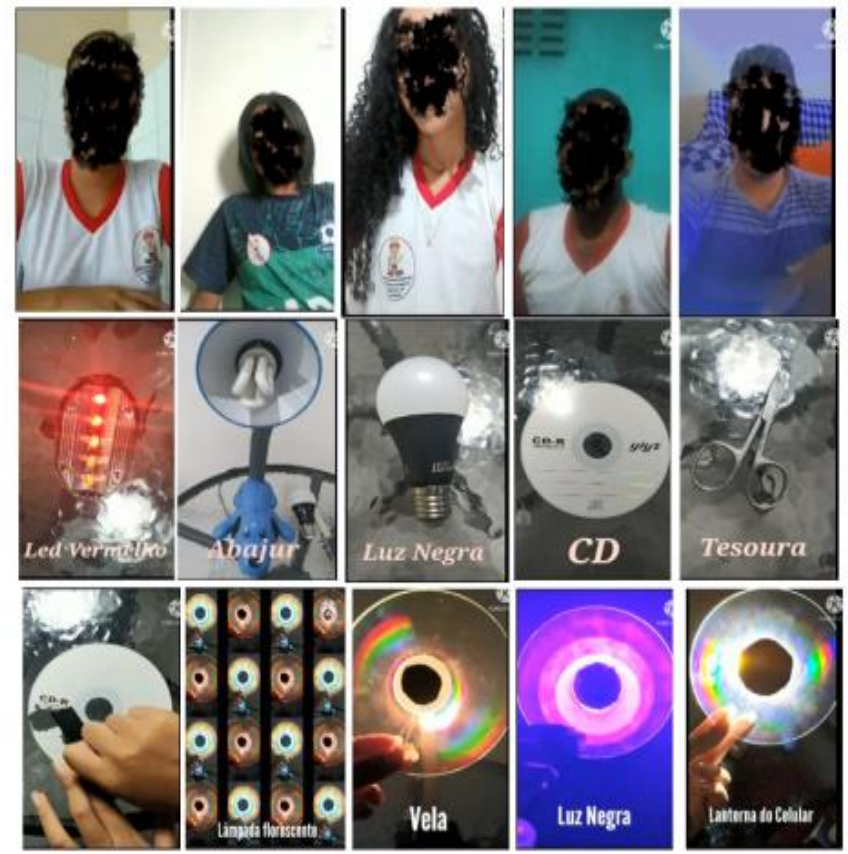

(2) trabalho exibido pela plataforma google meet. Experimentos (1) lâmpada de larva e (2) reflexão da luz.
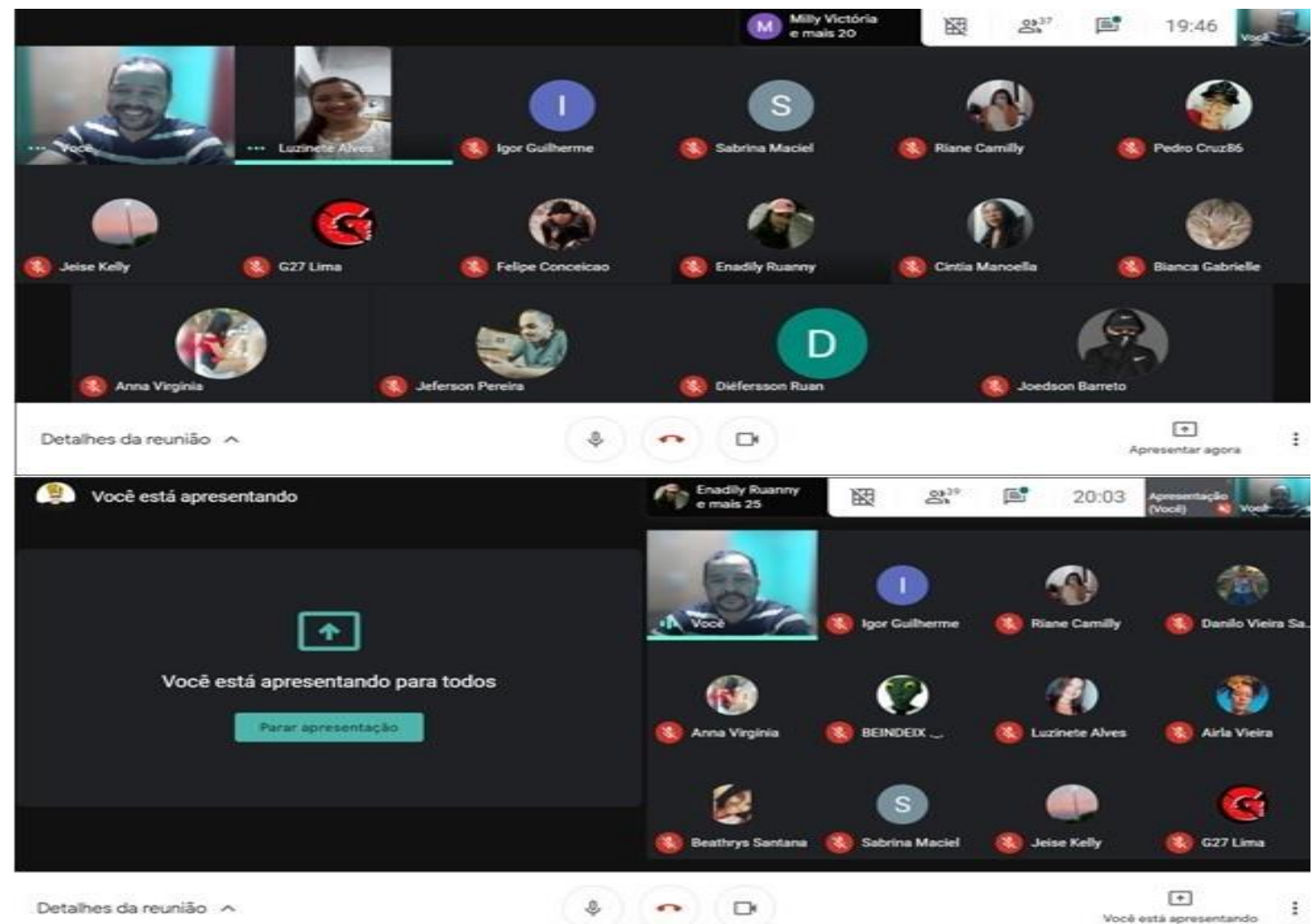

Fonte: Autoria própria. 
Live de apresentação dos experimentos realizados em casa pelos alunos do Centro educacional profissionalizante Marcelo deda chagas.

\section{CONSIDERAÇÕES FINAIS}

As atividades experimentais com certeza são as formas mais atraentes que podemos utilizar nas ciências da natureza para que possamos verificar certos fenômenos naturais que são ligeiramente inacessíveis ou de certa forma difíceis de serem visualizados. A experimentações com materiais simples foram com certeza fundamentais para o aprendizado dos

\section{REFERÊNCIAS}

Pandemia faz famílias valorizarem mais os professores. Fundação Lemann. Pesquisa

DATA FOLHA, 2020- disponível em: <https://fundacaolemann.org.br/noticias/pa ndemia-faz-familias-valorizaremmaisosprofessores?gclid=CjwKCAiAuoqA BhAsEiwAdSkVVMDlxb0a9asI1As7qjw Miz13Y59g1ZH9Z64k1X4MO_1VkMH3H_dwhoC_90QA vD_BwE>

COSTA, R. P. S. A nova realidade do ensino remoto na educação brasileira. 2020. disponível em:

<http://www.oabes.org.br/artigos/a-novarealidade-do-ensino-remoto-na-educacaobrasileira-81.html>

CARDOSO, D. C.; TAKAHASHI, E. K. Experimentação remota em atividades de ensino formal: um estudo a partir de periódicos Qualis A. Revista Brasileira de
Lives realizada dia 07, 14, 21, 28 /01/2001 pela plataforma google meet com a participação dos estudantes e dos professores convidados para apreciação dos trabalhos experimentais dos estudantes.

estudantes nesse distanciamento social. Todavia não há como negar que atividades amostrais realizadas em laboratórios das escolas são mais previsíveis e apresentam a colaboração e participação de todos os indivíduos que os realizam. De fato, essas atividades realizadas com materiais encontrados em casa são foram bem aproveitadas, pois tornaram os estudantes protagonistas de seus aprendizados.

Pesquisa em Educação em Ciências Vol. 11, N o 3, 2011

LAGARTO et al. Guia de boas práticas de ensino online em contexto de emergência para alunos surdos durante a pandemia da doença covid- 19.

Guidelines 2020 para Ministério da educação/ direção-geral da educação.

Universidade católica portuguesa: Instituto de Ciências da Saúde Faculdade de Ciências Humanas Disponível em: <https://www.dge.mec.pt/sites/default/files Iguia_de_boas_praticas_de_ensino_online em_contexto_de_emergencia_para_aluno s_surdos_durante_a_pandemia_da_doenca _covid_19.pdf>

RODRIGUES, J. J. V.

EXPERIMENTAÇÃO NO ENSINO E APRENDIZAGEM DE FÍSICA. Fundação CECIERJ. REVISTA: Educação pública. 2018. ISSN 1984-6290. B3 em ensino Qualis, capes. Doi.10.18264/REP. DISPONIVEL EM: 
https://educacaopublica.cecierj.edu.br/artig os/18/9/experimentao-no-ensino-eaprendizagem-de-fsica.

MEDEIROS, A. P. G. et al. ATIVIDADES EXPERIMENTAIS NO ENSINO DE FÍSICA: UMA FORMA LÚDICA DE APRENDIZAGEM COM MATERIAIS DE BAIXO CUSTO. Anais VII ENALIC 2018. Fortaleza - CE - Disponível em: $<$ httpeditorarealize.com. brartigovisualizar51911>.

RAMOS, Eugenio Maria de França. Brinquedos e Jogos no Ensino de Física, dissertação (mestrado), USP: São Paulo, 1990.

FORÇA, A.C. et al. ATIVIDADES EXPERIMENTAIS NO ENSINO DE FÍSICA: TEORIA E PRÁTICAS. 2019. Programa de MECEM da Universidade Estadual de Londrina-PR. Departamento de Física da Universidade Estadual de Londrina-PR. Disponível em: <
httploos.prof.ufsc.brfiles201603ATIVIDA DES-EXPERIMENTAIS-NO-ENSINODE-F\%C3\%8DSICA-TEORIA-EPR\%C3\%81TICAS.pdf $>$.

LEIRIA, T. F.; MATARUCO, S. M. C. O PAPEL DAS ATIVIDADES EXPERIMENTAIS NO PROCESSO ENSINO-APRENDIZAGEM DE FÍSICA. XII EDUCERE - CONGRESSO NACIONAL DE EDUCAÇÃO. V SEMINARIO INTERNACIONAL SOBRE PROFISSIONALIZAÇÃO DOCENTE- SIPO - CATEDRA UNESCO.2015. DISPONIVEL EM: < httpseducere.bruc.com.brarquivopdf 20151 8234_8366.pdf >

RODRIGUES, D. C. G. A. A Inserção de Atividades Experimentais no Ensino de Ciências em Nível Médio: Um Relato de Sala de Aula. REVISTA PRÁXIS. ano I, nº 2 - agosto 2009. Disponível em: < httprevistas.unifoa.edu. brindex. phppraxisarticleview8701004 > 